\title{
Effect of Amino-Acids on Secretion of Insulin by Isolated Islets of the Monkey
}

\author{
S. Gunasekaran and P.Zachariah \\ Department of Physiology, Christian Medical College, Vellore, India
}

\begin{abstract}
Summary. Insulin secretion was monitored in monkey islets isolated by collagenase digestion and exposed to leucine and arginine with and without glucose. Leucine by itself (10 to $40 \mathrm{mmol} / \mathrm{l}$ ) elicited concentration-dependent insulin secretion. At $40 \mathrm{mmol} / \mathrm{l}$, leucine was approximately $60 \%$ as effective as glucose $(16.7 \mathrm{mmol} / \mathrm{l})$. The response to leucine was increased at low glucose concentrations. In high concentrations (20 and $40 \mathrm{mmol} / \mathrm{l}$ ), arginine by itself was a poor stimulant.
\end{abstract}

The effect of arginine was enhanced at low glucose concentrations $(2.8$ to $5.6 \mathrm{mmol} / \mathrm{l})$. At high glucose concentrations neither amino-acid produced any significant further increase in insulin release.

Key words: Isolated monkey islets, insulin secretion, glucose, leucine, arginine.
The extensive information available on the secretion of insulin and its regulation is mainly based on studies on islets from small laboratory animals, particularly the rat and the mouse. However, there is evidence for species variation in insulin secretory characteristics [1]. Because of the technical difficulties in isolating islets from primates [2] (including the paucity of experimental animals), simian islets have not been studied extensively. We have previously reported a method for isolation of monkey islets [3]. The secretory response of this preparation to glucose was closer to that of human than to that of rodent islets. We now report on the insulin secretory response of isolated monkey to certain amino-acids.

\section{Materials and Methods}

The methodology for the study of insulin secretion in isolated monkey islets was as reported earlier [3]. L-leucine and L-arginine hydrochloride were obtained from Sigma Chemicals, St. Louis, Missouri, USA. The medium for isolation and incubation of islets was Krebs bicarbonate. Until the beginning of pre-incubation, the pancreas and the islets were handled at $5{ }^{\circ} \mathrm{C}$ except for collagenase digestion at $37^{\circ} \mathrm{C}$. The duration of pre-incubation was $30 \mathrm{~min}$ in low glucose medium $(2.8 \mathrm{mmol} / 1)$

Statistical analysis was by Student's t-test.

\section{Results}

\section{Leucine-Induced Insulin Secretion}

Following pre-incubation, the islets were incubated in media containing various concentrations of leucine and/or glucose for $60 \mathrm{~min}$ (Table 1). The basal rate of insulin secretion of these islets, in the absence of any stimuli, can be taken to be $0.2 \mathrm{ng} \cdot \mathrm{h}^{-1} \cdot$ islet $^{-1}$ as shown by islets incubated in the low glucose medium alone. Leucine by itself produced a dose-related insulin secretion. The increase in insulin secretion, though small, is highly significant $(p<0.001)$. With leucine $(40 \mathrm{mmol} /$ 1 ), insulin secretion was approximately $60 \%$ of the maximal response to glucose. The presence of low glucose concentrations enhanced the insulin secretory response to leucine, but at high concentrations of glucose and leucine, the interaction between the two is less marked.

Table 1. Effect of leucine and glucose on insulin secretion in isolated monkey islets

\begin{tabular}{llll}
\hline & \multicolumn{2}{l}{ Insulin secretion $\left(\mathrm{ng} \cdot \mathrm{h}^{-1} \cdot\right.$ islet $\left.^{-1}\right)$} \\
\cline { 2 - 4 } $\begin{array}{l}\text { Glucose } \\
\text { (mmol/1) }\end{array}$ & \multicolumn{2}{l}{ Leucine concentrations } & $40 \mathrm{mmol} / \mathrm{I}$ \\
\cline { 2 - 4 } & 0 & $10 \mathrm{mmol} / \mathrm{l}$ & $1.41 \pm 0.05$ \\
\hline $0^{\mathrm{a}}$ & - & $0.47 \pm 0.03$ & $1.82 \pm 0.05$ \\
2.8 & $0.20 \pm 0.01$ & $0.81 \pm 0.03$ & $1.90 \pm 0.05$ \\
5.6 & $0.71 \pm 0.03$ & $1.21 \pm 0.03$ & $2.11 \pm 0.10$ \\
11.1 & $1.52 \pm 0.05$ & $1.81 \pm 0.04$ & $2.40 \pm 0.11$ \\
16.7 & $2.25 \pm 0.13$ & $2.31 \pm 0.12$ & \\
\hline
\end{tabular}

Values are expressed as mean $\pm \mathrm{SEM}$ of six experiments.

a Islets exposed only to leucine $(20$ and $30 \mathrm{mmol} / \mathrm{l})$ secreted $0.91 \pm 0.04$ and $1.21 \pm 0.05 \mathrm{ng}$ insulin $\cdot \mathrm{h}^{-1} \cdot$ islet $^{-1}$ respectively 
Table 2. Insulin release by arginine and glucose in isolated monkey islets

\begin{tabular}{lccc}
\hline & \multicolumn{3}{l}{ Insulin secretion $\left(\mathrm{ng} \cdot \mathrm{h}^{-1} \cdot\right.$ islet $\left.^{-1}\right)$} \\
\cline { 2 - 4 } $\begin{array}{l}\text { Glucose } \\
\text { (mmol/l) }\end{array}$ & \multicolumn{3}{l}{ Arginine concentrations } \\
\cline { 2 - 4 } & 0 & $20 \mathrm{mmol} / 1$ & $40 \mathrm{mmol} / 1$ \\
\hline 0 & - & $0.47 \pm 0.03$ & $0.58 \pm 0.03$ \\
2.8 & $0.19 \pm 0.03$ & $0.92 \pm 0.03$ & $1.05 \pm 0.04$ \\
5.6 & $0.75 \pm 0.02$ & $1.04 \pm 0.07$ & $1.25 \pm 0.08$ \\
11.1 & $1.25 \pm 0.08$ & $1.32 \pm 0.10$ & $1.49 \pm 0.11$ \\
16.7 & $2.15 \pm 0.12$ & $2.16 \pm 0.19$ & $2.18 \pm 0.11$ \\
\hline
\end{tabular}

Values are expressed as mean \pm SEM of ten experiments. The islets were pre-incubated in basal low glucose medium $(2.8 \mathrm{mmol} / \mathrm{l})$ during 0-30 min

\section{Arginine Induced Insulin Secretion}

Following pre-incubation, groups of islets were exposed for $60 \mathrm{~min}$ to different concentrations of glucose or arginine. As shown in Table 2, the rate of insulin secretion was twice as much with arginine $(20 \mathrm{mmol} / \mathrm{l})$ as with low glucose $(p<0.001)$. On increasing the concentration of arginine from 20 to $40 \mathrm{mmol} / \mathrm{l}$, there was a slight increase in insulin secretion. Even so, this response was only $25 \%$ of the maximal insulin secretory response to glucose alone. When the medium contained a low concentration of glucose $(2.8 \mathrm{mmol} / \mathrm{l})$ which by itself is not insulinogenic, the response to arginine $(20 \mathrm{mmol} / \mathrm{l})$ was greatly enhanced. Doubling the arginine concentration under these conditions produced a slight but significant increase in insulin secretion $(p<$ $0.05)$. When glucose $(5.6 \mathrm{mmol} / \mathrm{l})$ was present in the medium, the secretory rates at both concentrations of arginine were higher than in the presence of glucose $(2.8 \mathrm{mmol} / \mathrm{l})$. When the islets were secreting substantial quantities of insulin in the presence of higher concentrations of glucose, addition of arginine seemed to produce little, if any, increase in insulin secretion.

\section{Discussion}

After glucose, the most important insulin secretagogues in most animals are amino-acids. Leucine and arginine are of particular interest. In all species studied so far, leucine has a 'primary' insulinogenic action (i.e. by itself and in the absence of other primary stimulants). Leucine stimulated insulin secretion in pieces of rabbit pancreas [4], pieces of rat pancreatic tissue [5] and in perfused rat pancreas [6]. The present observations show that, in monkeys also, leucine is a primary stimulant, the effective stimulatory concentrations ranging from 10 to $40 \mathrm{mmol} / \mathrm{l}$. The response of monkey islets to leucine in the present studies is comparable to that observed by Grant et al. using isolated human islets [7]. There is a qualitative similarity between the monkey and rodent islets in the response to leucine [8].
In the present studies as well as in other observations, the maximal insulin secretory capacity of primate islets at high glucose concentration has seldom exceeded about $2 \mathrm{ng} \cdot \mathrm{h}^{-1} \cdot$ islet $^{-1}[9,10]$. Thus the maximal observed response of monkey islets to leucine alone $1.41 \mathrm{ng} \cdot \mathrm{h}^{-1} \cdot$ islet $^{-1}$ ) is approximately $60 \%$ of their maximal response to glucose. In the case of rodent islets the maximum stimulation by leucine is only $20-30 \%$ of that found for glucose [8]. Thus it would seem that primate islets are relatively as sensitive to leucine as are rodent islets.

Low glucose concentrations potentiated the leucineinduced insulin release in rat pancreatic tissue [5], isolated islets from obese hyperglycaemic mice [8], and perfused rat pancreas [6]. Higher glucose concentrations did not further enhance the rate of insulin secretion induced by leucine. This is comparable with our findings in monkey islets.

The observations on the action of arginine on monkey islets are of special interest. In pieces of rabbit pancreas [11], isolated rat islets [12] and micro-dissected islets of obese hyperglycaemic mice [13], arginine has been shown to be capable of releasing insulin only in the presence of glucose, and not by itself. However, this phenomenon was not observed by Hertelendy et al. [14] in isolated sheep pancreas. In this species they found that arginine could stimulate insulin secretion in the absence of glucose.

In the present studies arginine by itself $(20 \mathrm{mmol} / \mathrm{l})$ stimulated the secretion of insulin to a small extent (Table 2). There is a further slight but significant increase in insulin secretion when the concentration of arginine was doubled. The effect of arginine $(20 \mathrm{mmol} / \mathrm{l})$ is no more than that of leucine $(10 \mathrm{mmol} / \mathrm{l})$ which is itself less than the response to glucose $(5.6 \mathrm{mmol} / \mathrm{l})$. The maximal insulin secretory rate induced by arginine is only about $25 \%$ of the maximal response to glucose. Thus it can be concluded that at high concentrations arginine is a poor primary stimulant in monkey islets.

In monkey islets the interaction between glucose and arginine depends upon the concentration used. Glucose at low concentrations $(2.8 \mathrm{mmol} / \mathrm{l})$ potentiates arginine, is additive at physiological concentrations of glucose $(5.6 \mathrm{mmol} / \mathrm{l})$ and there is no additive effect between these stimulants at higher concentrations.

We have described previously one peculiarity of isolated monkey islets, namely the low insulin secretory response to glucose when compared with islets of smaller laboratory animals. The present study shows a similar small response to leucine and arginine even though these are also primary insulinogenic stimulants in monkeys. However the relative sensitivity to amino-acids, when compared with glucose, is similar in primates and rodents.

Acknowledgement. S. Gunasekaran is a Junior Research Fellow of the Indian Council of Medical Research. The work was partly supported by the Fluid Research Fund of the Christian Medical College, Vellore. 


\section{References}

1. Feldman JM (1979) Species variation in the islets of Langerhans. Diabetologia 16: 1-4

2. Jonasson O, Reynolds WA, Snyder G, Hoversten G (1977) Experimental and clinical therapy of diabetes by transplantation. Transplant Proc 9: 223-232

3. Gunasekaran S, Zachariah P (1979) Studies on insulin secreted by isolated islets of the monkey, Macaca radiata radiata. Diabetes 28: 865-869

4. Milner RDG (1969) Stimulation of insulin secretion in vitro by essential amino acids. Lancet 1: 1075-1076

5. Malaisse WJ, Malaisse-Lagae F (1968) Stimulation of insulin secretion by noncarbohydrate metabolites. J Lab Clin Med 72: $438-448$

6. Landgraf R, Landgraf-Leurs MMC, Horl R (1974) L-Leucine and L-phenylalanine induced insulin release and the influence of D-glucose. Diabetologia 10: 415-420

7. Grant AM, Christie MR, Ashcroft SJH (1980) Insulin release from human pancreatic islets in vitro. Diabetologia 19:114-117

8. Lernmark A (1972) Specificity of leucine stimulation of insulin release. Hormones 3: 14-21

9. Ashcroft SJH, Bassett JM, Randle PJ (1971) Isolation of human pancreatic islets capable of releasing insulin and metabolising glucose in vitro. Lancet 1:888-889

10. Lundgren G, Anderson A, Borg H, Buschand K, Groth CG, Gunnarsson R, Hellerstrom C, Petersson B, Ostman J (1977) Structural and functional integrity of isolated human islets of Langerhans maintained in tissue culture for 1-3 weeks. Transplant Proc 9: $237-240$

11. Milner RDG (1970) The stimulation of insulin release by essential amino acids from rabbit pancreas in vitro. $\mathbf{J}$ Endocrinol 47 : 347-356

12. Norfleet WT, Pagliara AS, Haymond MW, Matschinsky F (1975) Comparison of $\alpha$ and $\beta$ cell secretory responses in islets isolated with collagenase and in the isolated perfused pancreas of rats. Diabetes 24:961-970

13. Lernmark A (1972) Effect of neutral and dibasic aminoacids on the in vitro release of insulin. Hormones $3: 22-30$

14. Hertelendy F, Machlin LJ, Takahashi Y, Kipnis DM (1968) Insulin release from sheep pancreas in vitro. J Endocrinol 41: 605-606

Received: 4 June 1981

and in revised form: 28 June 1982

Professor P.Zachariah

Department of Physiology

Christian Medical College

Vellore-632 002

S. India 